\title{
Trauma oclusal antes, durante e depois do tratamento ortodôntico: aspectos morfológicos de sua manifestação
}

\author{
Alberto Consolaro*
}

O trauma oclusal pode ser definido como a lesão periodontal induzida pela pressão dos dentes antagonistas, quer seja direta ou indiretamente. $\mathrm{O}$ trauma oclusal também pode ser definido como a lesão induzida nos tecidos de inserção dentária decorrente de forças oclusais excessivas.

As especificidades do trauma oclusal não permitem que possa ser comparado ao traumatismo dentário e, muito menos ainda, ao movimento dentário induzido para finalidades ortodônticas. $O$ trauma oclusal, o traumatismo dentário e o movimento ortodôntico são situações clínicas distintas, assim como as alterações teciduais induzidas. Alguns especialistas de outras áreas chegam a comparar, equivocadamente, a movimentação dentária induzida com algo semelhante ao traumatismo dentário e ao trauma oclusal. Provavelmente, isso decorre de desconhecimento sobre a biopatologia da movimentação ortodôntica, do trauma oclusal e do traumatismo dentário e, talvez, porque são três situações que têm em comum o fato de serem promovidas por agentes físicos, daí a confusão conceitual se estabelece.

Para facilitar a diferenciação e a compreensão dos eventos e sinais do trauma oclusal, dividimos sua evolução em quatro momentos.

\section{PRIMEIRO MOMENTO}

No primeiro momento, o trauma oclusal primário pode ser assintomático ou subclínico. Em muito casos produz, inicialmente, uma sintomatologia caracterizada por dor difusa associada a um discreto aumento da mobilidade dentária, que pode durar dias, semanas e até meses. No ligamento periodontal, poderemos encontrar um discreto edema e infiltrado celular, caracterizando uma inflamação crônica inespecífica e difusa, identificada como pericementite crônica.

\section{SEGUNDO MOMENTO}

No segundo momento, algumas semanas depois de iniciado o processo, pode-se notar, radiograficamente, o alargamento uniforme do espaço periodontal, com espessamento da lâmina dura que representa a cortical óssea alveolar (Fig. 1, 2, 3). Estas imagens radiográficas ocorrem em conseqüência da necessidade de fibras periodontais mais espessas e mais longas para suportar um aumento da função, ou seja, para absorver as forças oclusais mais intensas. Aumenta-se, assim, a espessura do ligamento periodontal. Ao mesmo tempo, estas fibras periodontais maiores requerem uma inserção igualmente maior, aumentando-se a espessura da

\footnotetext{
* Professor na graduação e pós-graduação da Faculdade de Odontologia de Bauru/USP. Professor na pós-graduação da Faculdade de Odontologia de Ribeirão Preto/USP.
} 


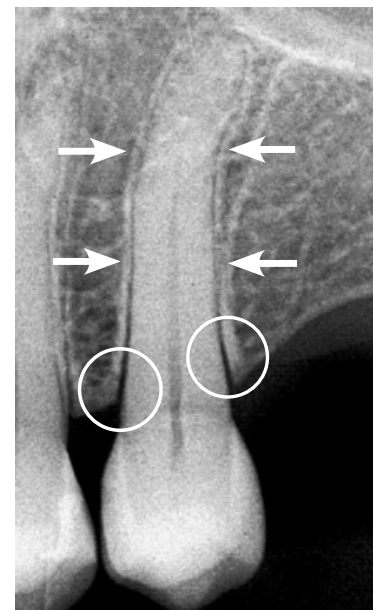

FIGURA 1 - Trauma oclusal caracterizado pelo espessamento da cortical óssea alveolar (setas) e do espaço periodontal. Na região cervical, o espessamento do espaço periodontal assume a forma de " $\mathrm{V}$ " bem fechado (círculos) e representa um estiramento maior dos tecidos ligamentares com ruptura eventual de fibras e acúmulo maior de mediadores, induzindo reabsorções ósseas mais aceleradas na parte mais cervical da face periodontal da crista óssea alveolar.

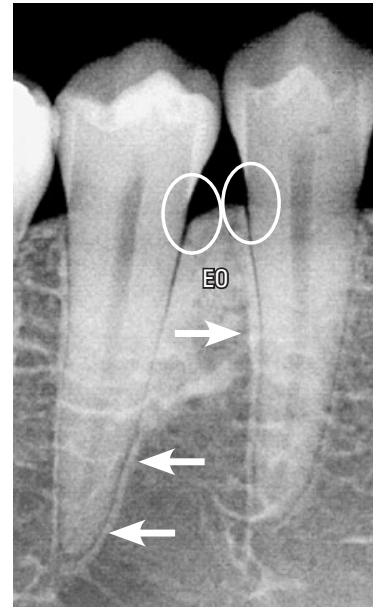

FIGURA 2 - Após semanas ou meses de trauma oclusal, um delicado "V" pode ser percebido na mesial do segundo pré-molar e na distal do primeiro pré-molar (círculos), associados a uma destacada esclerose óssea (EO) da maior parte da crista óssea interdentária e com espessamento da cortical óssea alveolar e do espaço periodontal em ambos os dentes (setas).

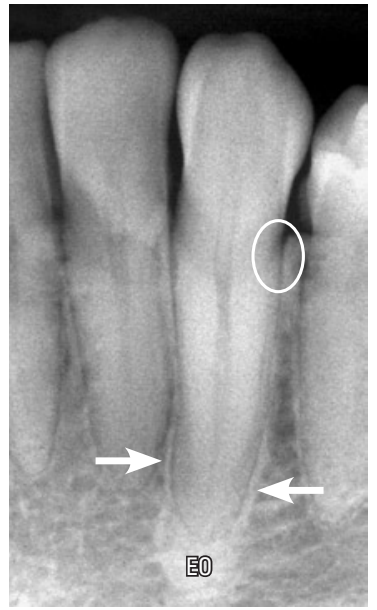

FIGURA 3 - Esclerose óssea periapical (EO) induzida pelo trauma oclusal, após aproximadamente 9 meses de duração. Na distal do canino inferior, observa-se a reabsorção óssea na crista interdentária em forma de "V" (círculo) e espessamento da cortical óssea alveolar e do espaço periodontal (setas).

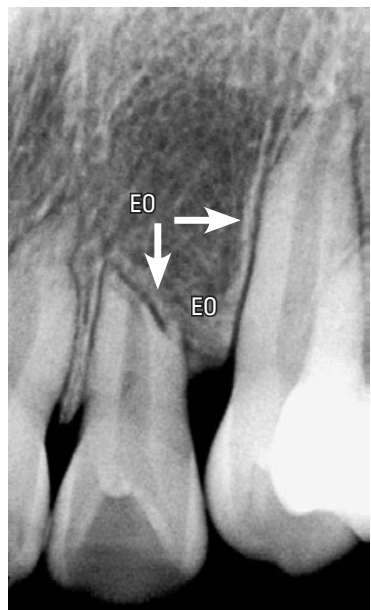

FIGURA 4 - Reabsorção radicular em plano, tipicamente induzida quando a guia lateral do canino incide no incisivo lateral, promovendo trauma oclusal por anos a fio. 0 s tecidos periodontais do incisivo lateral não resistem às cargas excessivas e cementoblastos morrem, permitindo a reabsorção dentária. Nota-se a esclerose óssea (EO), espessamento da cortical óssea alveolar (setas) e espessamento irregular do espaço periodontal no incisivo lateral e no canino. cortical óssea alveolar para suprir esta necessidade, o mesmo devendo ocorrer no cemento, mas neste não é possível se observar alterações nos exames imaginológicos.

\section{TERCEIRO MOMENTO}

Semanas ou meses depois, caracterizando-se um terceiro momento na evolução do trauma oclusal, a continuidade da demanda funcional aumentada pela força oclusal excessiva promove um estiramento intenso e repetitivo das fibras periodontais, especialmente as cervicais, que se inserem na parte mais cervical da crista óssea alveolar (Fig. $1,2,3)$. Esta sobrecarga pode romper eventuais feixes colágenos, estressar excessivamente as células do ligamento periodontal e, em decorrência, aumentar significantemente o nível local de mediadores químicos por elas liberados, principalmente os associados à reabsorção óssea local, promovendo-se a perda óssea vertical ou angulada da face periodontal na crista óssea alveolar.

Radiograficamente, adiciona-se ao quadro imaginológico a perda óssea vertical com formação de um "V" típico do trauma oclusal, formado pelo plano ósseo reabsorvido e pela parede radicular (Fig. 2, 3). As radiografias periapicais servem para este diagnóstico, mas as interproximais são mais precisas. Por maior que seja a perda óssea vertical nesta área, a sondagem periodontal não revelará bolsa periodontal. Se neste estágio houver remoção do trauma oclusal, haverá neoformação óssea periodontal e volta à normalidade. Todos estes eventos decorrem das forças oclusais excessivas em um ambiente livre de placa dentobacteriana; por isso mesmo, o conjunto destas alterações é denominado "trauma oclusal primário".

As modificações radiográficas refletem os fenômenos que ocorrem no espaço interdentário, 
mas nas faces livres, como a vestibular, dependendo da espessura da cortical ou tábua óssea vestibular, a perda óssea vertical resulta na perda local do nível ósseo vestibular, formando-se uma deiscência óssea sobre a raiz envolvida, uma depressão deste contorno ósseo em forma de "V", retirandose localmente o suporte ósseo do tecido gengival.

Mesmo com a perda óssea vertical no espaço interdentário, não haverá bolsa periodontal, mas na face vestibular pode-se notar, clinicamente, que o contorno gengival vai acompanhando o contorno ósseo vestibular, tendo-se como conseqüência as recessões gengivais em forma de "V", ou angulares, nos dentes em trauma oclusal e com deiscências ósseas. Destaca-se, mais uma vez, a falta de associação do processo com o acúmulo local de placa dentobacteriana e decorrente doença periodontal inflamatória crônica.

Clinicamente, observa-se um discreto aumento da mobilidade dentária, facetas de desgaste oclusal ou incisal típicas da atrição acentuada e a presença de recessões em forma de "V", mas um quarto sinal pode ser adicionado: a abfração.

O esmalte extremamente cristalizado não consegue acompanhar as deformações excessivas que as forças oclusais impõem à dentina. $\mathrm{O}$ esmalte tem uma estrutura quase exclusivamente mineral, com 95\% de parte inorgânica e sem maleabilidade, enquanto a dentina tem aproximadamente 40\% de parte orgânica e água. Esta dissonância entre $o$ esmalte e a dentina na absorção das forças excessivas promove microfraturas adamantinas na região cervical, com perda de pequenos fragmentos e micro-exposições de dentina. A abfração acrescenta, ao quadro clínico de trauma oclusal, a perda cervical do esmalte e a sensibilidade aumentada frente aos fatores bucais variáveis, como alimentação, líquidos, respiração, temperatura e outros. Em seu início, a abfração não é clinicamente detectável, a não ser pela hipersensibilidade aparentemente inexplicável.

Em muitos casos, a recessão gengival em forma de "V" acaba sendo atribuída à forma de escovação incorreta por parte do paciente, o mesmo ocorrendo com a abfração, confundida com freqüência com a abrasão e com a erosão dentária. Uma vez detectada a abfração, deve-se pesquisar os outros sinais clínicos e radiográficos de trauma oclusal.

\section{QUARTO MOMENTO}

No quarto momento do trauma oclusal, depois de muitos meses e até anos de persistência das forças oclusais excessivas, o osso periférico à cortical óssea alveolar, ou lâmina dura, gradativamente espessa suas trabéculas e áreas de esclerose aparecem ao redor da raiz afetada, distribuídas de forma irregular ou concentrada na lateral e/ou na região apical (Fig. 2, 3, 4). Essa também é uma reação tecidual óssea frente ao aumento da demanda funcional com longa duração. O osso esclerosado, agora mais denso, deixa de absorver parte das forças oclusais, que cada vez mais se concentram no ligamento periodontal. Haverá, a partir deste momento, uma agressão cada vez maior e direta sobre as estruturas periodontais, com prováveis danos focais à camada de cementoblastos que protegem as raízes da reabsorção, por sua falta de receptores de membrana para os mediadores da reabsorção óssea. Nestas regiões da superfície, micro-áreas de reabsorção radicular ocorrem, se somam e, gradativamente, se expressam como imagens radiográficas (Fig. 4).

Assim, nas fases finais de evolução de um trauma oclusal, depois de meses e meses de ocorrência, ou mesmo anos, a reabsorção radicular, geralmente em plano, pode fazer parte do seu quadro imaginológico (Fig. 4). As reabsorções radiculares induzidas pelo trauma oclusal muitas vezes são consideradas idiopáticas ou resultantes de traumatismo dentário.

\section{OS QUATRO MOMENTOS: SIMULTÂNEOS E/OU SEQÜENCIAIS}

Assim, caracterizamos as lesões decorrentes do trauma oclusal em quatro momentos, cada um com suas características, mas que, na maioria das 
situações, se superpõem, pois correspondem a um mesmo processo, assim dividido apenas para facilitar a compreensão. O desconforto sintomatológico nem sempre está presente e em muitos casos o paciente acomoda-se; o trauma oclusal, por ser subclínico, pode evoluir silenciosamente para conseqüências mais graves.

\section{O TRAUMA OCLUSAL ANTES E DURANTE O TRATAMENTO ORTODÔNTICO}

O desajuste oclusal; a interferência com desgaste excessivo, resultando em facetas e severas perdas de estrutura dentária - como a atrição; e a abfração podem fazer com que o trauma oclusal possa justificar a indicação do caso clínico para o tratamento ortodôntico.

Durante a movimentação dentária ortodôntica, podem ocorrer interferências e traumas oclusais, mas que representam fases breves do processo, que não se completará. A sintomatologia pode se fazer presente, inclusive com mobilidade dentária aumentada, mas severas perdas de estrutura dentária e reabsorções radiculares não acontecerão, pois não haverá tempo suficiente para que isto se estabeleça. Logo, o movimento dentário induzido colocará o dente em posição normal. Em alguns casos, pode ser necessária a confecção de placas de alívio e até desgastes de estruturas exuberantes - como cristas, cúspides e cíngulos -, mas apenas em situações muito especiais, que devem ser bem estudadas e planejadas.

\section{O TRAUMA OCLUSAL APÓS O TRATAMEN- TO ORTODÔNTICO}

Infelizmente, ainda não são muitos os profissionais que, depois de "completado" o tratamento ortodôntico, fazem uma minuciosa análise oclusal, avaliam as possíveis interferências e promovem os ajustes necessários para o paciente ter alta com uma oclusão aceitável. Muitos profissionais acreditam que esta análise e preocupação não são necessárias porque ao longo de seis meses após o tratamento ortodôntico haverá um ajuste oclusal acomodativo e natural.

Quantos pacientes, ao término do tratamento ortodôntico, apresentam interferências oclusais?

E depois de seis meses, um ou dois anos de tratamento ortodôntico, quantos pacientes apresentam trauma oclusal diagnosticável clínica e radiograficamente?

São muitos os casos de reabsorções radiculares que continuam ou ocorrem após o tratamento ortodôntico ter sido "completado". Muitos destes dentes também podem apresentar facetas de desgaste, recessão gengival em forma de "V" e/ou abfração. Quase sempre são dentes que estão em trauma oclusal, cuja reabsorção radicular, dano gengival e abfração poderiam ter sido evitados com uma análise oclusal criteriosa logo após a remoção do aparelho ortodôntico.

\section{CONSIDERAÇÃO FINAL}

Muitos profissionais podem não estar aptos para o diagnóstico preciso da abfração e da recessão gengival em forma de "V" como manifestações clínicas do trauma oclusal, o mesmo ocorrendo com as alterações imaginológicas induzidas e descritas. Mas uma análise oclusal criteriosa faz parte do tratamento ortodôntico e, apenas depois de uma oclusão normal obtida, o paciente deve receber alta e o caso ser considerado completado.

Quantos trabalhos foram publicados nos últimos anos relacionando a análise oclusal criteriosa, os sinais clínicos e radiográficos de trauma oclusal e a finalização de casos ortodonticamente tratados, imediatamente após e depois de 6 e 12 meses da alta do paciente?

Endereço para correspondência

Alberto Consolaro

E-mail: consolaro@uol.com.br 